(2) Open Access Full Text Article

REVIEW

\title{
Development, clinical utility, and place in therapy of posaconazole for prevention and treatment of invasive fungal infections
}

This article was published in the following Dove Press journal:

Drug Design, Development and Therapy

3 November 2010

Number of times this article has been viewed

\author{
Emily Zoller \\ Connie Valente \\ Kyle Baker \\ Michael E Klepser \\ Ferris State University College of \\ Pharmacy, Kalamazoo, Michigan, USA
}

\begin{abstract}
Posaconazole is an extended-spectrum azole antifungal that exhibits activity against a broad range of fungal pathogens, including yeasts and moulds. Clinical data have demonstrated the clinical utility of posaconazole against many therapy-refractory pathogens, including Aspergillus spp, Fusarium spp, and Zygomycetes. These data have provided clinicians with hope in these difficult situations. Some of the limitations that have emerged with the use of posaconazole are the lack of an intravenous formulation and erratic drug absorption. This fact is further complicated by the existence of saturable posaconazole absorption. Despite these drawbacks, posaconazole appears poised to become a prominent therapeutic modality for the prophylaxis and management of various fungal infections among high-risk patients.
\end{abstract}

Keywords: posaconazole, pharmacokinetics, fungal infections

\section{Introduction}

In recent years, the incidence of invasive fungal infections has increased dramatically. While this can be contributed to multiple factors, advances in medical technology appear to have had the most dramatic effect. ${ }^{1,2}$ Although medical breakthroughs have improved the survival of patients with a variety of life-threatening illnesses, these same advances have simultaneously created populations at increased risk for acquiring invasive fungal infections. ${ }^{2,3}$ Examples of these extremely susceptible patient groups include human immunodeficiency virus (HIV)-infected individuals, solid organ and hematopoietic stem cell transplant recipients, oncology patients, thermal injury patients, individuals with indwelling medical devices, and low-birth-weight infants. ${ }^{2}$

Historically, Candida and Aspergillus were the two most prominent fungal species to cause human infections. Although Candida species are still the fourth most common cause of nosocomial blood stream infections, various other moulds and yeasts are becoming increasingly more common. ${ }^{2,4,5}$ Infection from previously rarely encountered organisms, such as Blastomyces dermatitidis, Coccidioides species, Fusarium species, Histoplasma capsulatum, and Zygomycetes are now more commonly encountered. ${ }^{4}$ Along with the emergence of infections caused by a broader array of fungal pathogens, increasing rates of drug resistance among Candida and Aspergillus spp to commonly used antifungal agents have been reported., These factors have complicated the management of fungal infections and have challenged clinicians to rethink empiric choices. ${ }^{1,3,5,6}$

For decades, amphotericin B had been considered the gold-standard antifungal for treatment of serious fungal infections. ${ }^{4}$ The broad spectrum of activity of amphotericin B has made it attractive for empiric therapy; however, associated toxicities have greatly
Correspondence: Michael E Klepser Ferris State University College of Pharmacy, I000 Oliver St, Kalamazoo, MI 49008, USA

Tel +l 2693877298

Fax + I 2693877187

Email klepserm@ferris.edu 
limited its use. ${ }^{1,4}$ The safety and tolerability of antifungal treatments improved significantly with the approval of the "first-generation" azoles, fluconazole and itraconazole., Fluconazole provided clinicians with a safe and effective alternative to amphotericin B. However, lack of activity against moulds, including Aspergillus species, and concerns over the emergence of fluconazole-resistant Candida species negatively impacted the use of flucaonazole., ${ }^{1,3-5}$ Although itraconazole exhibits superior activity against some moulds compared with fluconazole, it still has poor activity against many emerging pathogens, such as Fusarium spp, Zygomycetes, and some Scedosporium spp. ${ }^{4}$ Furthermore, erratic absorption and delayed availability of an intravenous formulation contributed to the negative stigma associated with itraconazole. The development of the "second-generation" triazoles, voriconazole and posaconazole, ushered in a new group of antifungal agents with enhanced spectrum of activity against moulds, including Aspergillus spp, Fusarium spp, and Scedosporium spp. ${ }^{1,5}$ Additionally, posaconazole possesses activity against some Zygomycetes. ${ }^{4}$ Owing to their broad spectrum of activity against emerging moulds and some fluconazole-resistant strains, clinical interest in these two agents has been substantial., ${ }^{1,5}$

This paper reviews the pharmacokinetic and clinical data for posaconazole. Other information needed to allow the clinician to make informed treatment decisions, including safety, tolerability, and quality of life data are also presented.

\section{Mechanism of action}

Posaconazole is an extended-spectrum triazole antifungal available for oral administration. ${ }^{7}$ Posaconazole exerts its activity by binding to and inhibiting lanosterol-14 $\alpha$-demethylase. As a result, the conversion of lanosterol to ergosterol is interrupted at one of the last steps of the biosynthesis pathway. Lanosterol-14 $\alpha$-demethylase is a member of the cytochrome P450 (CYP450) enzyme family, and is found in nearly all types of fungi. Ergosterol is responsible for helping maintain the cellular membrane activity and integrity of fungi, and is not found in human cellular membranes, making its production an excellent target for antifungal therapy. ${ }^{7,8}$ Interference in the production of ergosterol disrupts the cellular membrane activity of fungi. However, because the interaction of posaconazole with CYP450 enzymes is not limited to lanosterol-14 $\alpha$-demethylase, posaconazole does have the potential to interfere with hepatic isoenzymes responsible for drug metabolism.
It is interesting to note that the chemical structure of posaconazole is larger than that of the other azoles. This characteristic is theorized to allow posaconazole to attach to multiple binding domains on the target enzyme and offer a lower affinity to drug efflux pumps. ${ }^{8-10}$

\section{Pharmacokinetics Absorption}

Posaconazole is currently available as a suspension for oral administration. This formulation was developed as a result of the finding that an oral suspension provided greater bioavailability than a tablet formulation. ${ }^{11}$ Despite the better bioavailability of the posaconazole suspension, absorption is still quite erratic. In a study of 56 healthy volunteers receiving a $400 \mathrm{mg}$ dose of the oral suspension, the steady-state area under the concentration-time curve (AUC) among subjects ranged from roughly 14,000 to $70,000 \mathrm{ng} \cdot \mathrm{h} / \mathrm{mL} .^{12}$ Furthermore, the coefficients of variation noted for AUCs and peak concentrations were roughly $40 \%{ }^{12}$ These observations highlight the tremendous variability associated with the absorption of posaconazole, even under the best of conditions. Several studies have attempted to determine the factors responsible for the enormous interpatient variability associated with the absorption of posaconazole. Subsequently, it was reported that low gastric $\mathrm{pH}$ and coadministration of the dose with a high-fat meal may increase posaconazole absorption by up to $400 \% .{ }^{13}$ In contrast, higher gastric $\mathrm{pH}$ and presence of diarrhea can decrease the absorption of posaconazole by up to $60 \% .{ }^{13,14}$ Additionally, underlying patient factors, such as bone marrow transplantation and mucositis, can also greatly contribute to inter- and intrapatient variability with respect to drug absorption. ${ }^{15,16}$

Another compounding element that has complicated attainment of predictable drug levels among patients was the identification of saturable absorption of posaconazole following oral administration. ${ }^{17}$ In a group of healthy adults, it was observed that plasma concentrations of posaconazole were maximized at doses of $800 \mathrm{mg} .{ }^{17}$ Similarly, in various patient populations, overall systemic exposure to posaconazole was found to plateau at doses of $200 \mathrm{mg}$ to $400 \mathrm{mg} .{ }^{15,16}$ In one study, 98 patients with proven or possible fungal disease were randomized to receive one of three posaconazole regimens, ie, $200 \mathrm{mg}$ four times daily for nine doses followed by $400 \mathrm{mg}$ twice daily, $400 \mathrm{mg}$ four times daily for nine doses followed by $600 \mathrm{mg}$ twice daily, or $800 \mathrm{mg}$ twice daily for five doses followed by $800 \mathrm{mg}$ once daily. ${ }^{16}$ Mean steady-state peak concentrations were $581 \mathrm{ng} / \mathrm{mL}, 579 \mathrm{ng} / \mathrm{mL}$, 
and $361 \mathrm{ng} / \mathrm{mL}$ for posaconazole dosed $400 \mathrm{mg}$ twice daily, $600 \mathrm{mg}$ twice daily, and $800 \mathrm{mg}$ once daily, respectively. Likewise $\mathrm{AUC}_{0-\tau}$ was $8619 \mathrm{ng} \bullet \mathrm{h} / \mathrm{mL}, 5823 \mathrm{ng} \bullet \mathrm{h} / \mathrm{mL}$, and $6199 \mathrm{ng} \cdot \mathrm{h} / \mathrm{mL}$ for posaconazole dosed $400 \mathrm{mg}$ twice daily, $600 \mathrm{mg}$ twice daily, and $800 \mathrm{mg}$ once daily, respectively. It was noted that the $400 \mathrm{mg}$ twice daily dose provided a $135 \%$ higher mean exposure than the $600 \mathrm{mg}$ twice daily dose, and a $182 \%$ higher mean exposure than the $800 \mathrm{mg}$ once daily dose $(P=0.0004, P<0.0001$, respectively). The authors of this study concluded that despite the long half-life of posaconazole, a dosing regimen of $400 \mathrm{mg}$ twice daily provided the highest overall systemic exposure to posaconazole. It has been hypothesized that a concentration-dependent first-pass effect and/or the poor solubility of posaconazole may contribute to this apparent saturable absorption.

\section{Distribution}

Posaconazole distributes extensively throughout the body. It has a reported volume of distribution of around $1774 \mathrm{~L}$ and is extensively bound to albumin (98\%). ${ }^{7}$ The volume of distribution has been reported to be somewhat less in older adults. ${ }^{12}$ This difference in volume of distribution may result in slightly greater exposure to posaconazole among older adults. However, owing to the large interpatient variability with respect to absorption, this observation is not likely to be clinically significant.

Interestingly, studies conducted in healthy and lung transplant recipients revealed that posaconazole achieves high levels in alveolar cells. ${ }^{18,19}$ In fact, the authors reported alveolar cell to peak plasma posaconazole ratios of $33: 1$ in healthy subjects and 55:1 in lung transplant recipients. ${ }^{18,19}$

\section{Metabolism}

Although posaconazole exerts its primary effects on 14- $\alpha$-demethylase, a CYP450-dependent enzyme, it does not appear to undergo extensive oxidative metabolism via hepatic CYP450 enzymes. ${ }^{7,20}$ Following administration of a radiolabeled dose of posaconazole in normal volunteers, it was reported that $77 \%$ and $14 \%$ cumulative radioactivity was recovered in the feces and urine, respectively. Approximately $66 \%$ of the excreted drug in the feces was the parent compound. In the plasma, the majority of radioactivity was associated with unchanged posaconazole. A glucuronide conjugate of posaconazole was the primary metabolite detected. These findings are in stark contrast with the metabolic profile of other triazole antifungals, such as voriconazole, which undergo a much greater degree of hepatic metabolism.

\section{Elimination}

The total body clearance of posaconazole is approximately $16 \mathrm{~L} /$ hour. $^{20}$ Renal clearance of posaconazole is negligible at $0.684 \mathrm{~mL} /$ hour, accounting for $<0.001 \%$ of the administered dose. ${ }^{20}$ Approximately $77 \%$ of the administered dose of posaconazole is recovered unchanged in the feces. ${ }^{20}$ Human and animal data strongly suggest that fecal excretion is the primary route of elimination of posaconazole..$^{20}$ The half-life of posaconazole is approximately 25-31 hours in healthy adults. ${ }^{13}$ Comparatively, the half-life of posaconazole was found to be similar among groups of patients with normal renal function and those with renal disease. including those undergoing hemodialysis. ${ }^{21}$ No trend regarding degree of hepatic impairment and total posaconazole exposure has been noted. ${ }^{22}$

\section{In vitro activity}

Posaconazole exhibits excellent in vitro activity against various fungi, including Candida spp, Cryptococcus neoformans, Aspergillus spp, Mucor spp, Rhizopus spp, Blastomyces spp, Coccidioides spp, Histoplasma spp, Paracoccidioides spp, Penicillium spp, Sporothrix spp, Trichophyton spp, and Pseudallescheria spp (Table 1). ${ }^{23-38}$ It has been reported that posaconazole retains activity against some fluconazole- and itraconazole-resistant fungi. ${ }^{32}$ Although posaconazole minimum inhibitory concentrations (MICs) for these azole-resistant isolates typically remained below $1 \mu \mathrm{g} / \mathrm{mL}$, it should be noted that a positive correlation is typically observed between posaconazole MICs and MICs to fluconazole. ${ }^{32,39}$ A notable exception to this trend is Candida krusei. ${ }^{32}$ Of a sample of 114 isolates of C. krusei with decreased susceptibility to fluconazole, 113 remained susceptible to posaconazole. ${ }^{32}$

Although posaconazole exhibits a broad spectrum of activity against moulds, some species, such as Aspergillus calidoustus, Fusarium oxysporum, and Scedosporium prolificans exhibit intrinsic in vitro resistance to posaconazole. ${ }^{38,40,41}$ Additionally, acquired resistance to posaconazole has emerged among previously susceptible pathogens, such as Aspergillus fumigatus, during the course of therapy. ${ }^{42}$ Commonly, posaconazole resistance in such isolates has been attributed to mutations in the CYP51A gene that alter the affinity of azoles for their target enzyme, lanosterol-14 $\alpha$-demethylase. ${ }^{42,43}$ It should be noted that, among isolates of $A$. fumigatus exhibiting mutations in the CYP51A gene, at least 18 different amino acid alterations have been noted. ${ }^{43}$ As a result, variable-resistance phenotypes have been 
Table I In vitro activity of posaconazole and select antifungal agents against various yeasts and moulds $\mathrm{s}^{23,32,35,38,40,41,72}$

\begin{tabular}{|c|c|c|c|c|}
\hline Drug/organism & $\mathrm{MIC}_{50}(\mu \mathrm{g} / \mathrm{mL})$ & $\mathrm{MIC}_{90}(\mu \mathrm{g} / \mathrm{mL})$ & Range $(\mu \mathrm{g} / \mathrm{mL})$ & Reference \\
\hline Candida albicans $(\mathrm{n}=2359)$ & & & & 32 \\
\hline Fluconazole & 0.25 & 0.5 & $0.12->128$ & \\
\hline Posaconazole & 0.03 & 0.03 & $0.007->8$ & \\
\hline Voriconazole & 0.007 & 0.015 & $0.007->8$ & \\
\hline Candida glabrata $(\mathrm{n}=607)$ & & & & 32 \\
\hline Fluconazole & 8 & 32 & $0.5->128$ & \\
\hline Posaconazole & I & 2 & $0.007->8$ & \\
\hline Voriconazole & 0.25 & 1 & $0.015-8$ & \\
\hline Candida parapsilosis $(n=439)$ & & & & 32 \\
\hline Fluconazole & I & 4 & $0.12-128$ & \\
\hline Posaconazole & 0.12 & 0.25 & $0.015-1$ & \\
\hline Voriconazole & 0.015 & 0.12 & $0.007-8$ & \\
\hline Candida tropicalis $(\mathrm{n}=319)$ & & & & 32 \\
\hline Fluconazole & 1 & 2 & $0.12->128$ & \\
\hline Posaconazole & 0.06 & 0.25 & $0.015->8$ & \\
\hline Voriconazole & 0.06 & 0.12 & $0.007->8$ & \\
\hline Candida krusei $(\mathrm{n}=114)$ & & & & 32 \\
\hline Fluconazole & 32 & 64 & $8-128$ & \\
\hline Posaconazole & 0.5 & I & $0.12-2$ & \\
\hline Voriconazole & 0.25 & 0.5 & $0.12-2$ & \\
\hline Candida lusitaniae $(n=42)$ & & & & 32 \\
\hline Fluconazole & 0.5 & 4 & $0.12-64$ & \\
\hline Posaconazole & 0.03 & 0.12 & $0.015-1$ & \\
\hline Voriconazole & 0.007 & 0.06 & $0.007-0.5$ & \\
\hline Cryptococcus neoformans $(n=373)$ & & & & 33 \\
\hline Fluconazole & 8 & 16 & $0.25->128$ & \\
\hline Itraconazole & 0.25 & 0.5 & $0.03-1$ & \\
\hline Posaconazole & 0.12 & 0.5 & $0.015-1$ & \\
\hline Aspergillus fumigatus $(\mathrm{n}=553)$ & & & & 40 \\
\hline Itraconazole & 0.5 & I & $0.12-2$ & \\
\hline Posaconazole & 0.25 & 0.5 & $0.03-2$ & \\
\hline Voriconazole & 0.25 & 0.5 & $0.06-4$ & \\
\hline Aspergillus flavus $(\mathrm{n}=76)$ & & & & 40 \\
\hline Itraconazole & 0.5 & 1 & $0.12-2$ & \\
\hline Posaconazole & 0.25 & 0.5 & $0.06-2$ & \\
\hline Voriconazole & 0.5 & I & $0.06-1$ & \\
\hline Aspergillus niger $(n=59)$ & & & & 40 \\
\hline Itraconazole & 2 & $>8$ & $0.5->8$ & \\
\hline Posaconazole & 0.25 & 1 & $0.12-2$ & \\
\hline Voriconazole & 0.5 & I & $0.12-2$ & \\
\hline Aspergillus terreus $(\mathrm{n}=35)$ & & & & 40 \\
\hline Itraconazole & 0.5 & 0.5 & $0.12-1$ & \\
\hline Posaconazole & 0.25 & 0.25 & $0.06-0.5$ & \\
\hline Voriconazole & 0.25 & 0.5 & $0.06-1$ & \\
\hline Aspergillus versicolor $(n=24)$ & & & & 40 \\
\hline Itraconazole & 1 & 2 & $0.12->8$ & \\
\hline Posaconazole & 0.5 & 1 & $0.006-2$ & \\
\hline Voriconazole & 0.25 & I & $0.03-2$ & \\
\hline Aspergillus calidoustus ( $n=4)$ & & & & 40 \\
\hline Itraconazole & 2 & NA & 0.122 & \\
\hline Posaconazole & 2 & NA & $0.25-8$ & \\
\hline Voriconazole & 2 & NA & $0.25-4$ & \\
\hline Rhizopus spp ( $\mathrm{n}=10 \mathrm{I})$ & & & & 23 \\
\hline Amphotericin B & 0.25 & 0.5 & $0.03-0.5$ & \\
\hline Itraconazole & 0.5 & 4 & $0.03->8$ & \\
\hline Posaconazole & 0.25 & I & $0.06-4$ & \\
\hline Voriconazole & 8 & $>8$ & $2->8$ & \\
\hline Caspofungin & $>16$ & $>16$ & $>16$ & \\
\hline
\end{tabular}


Table I (Continued)

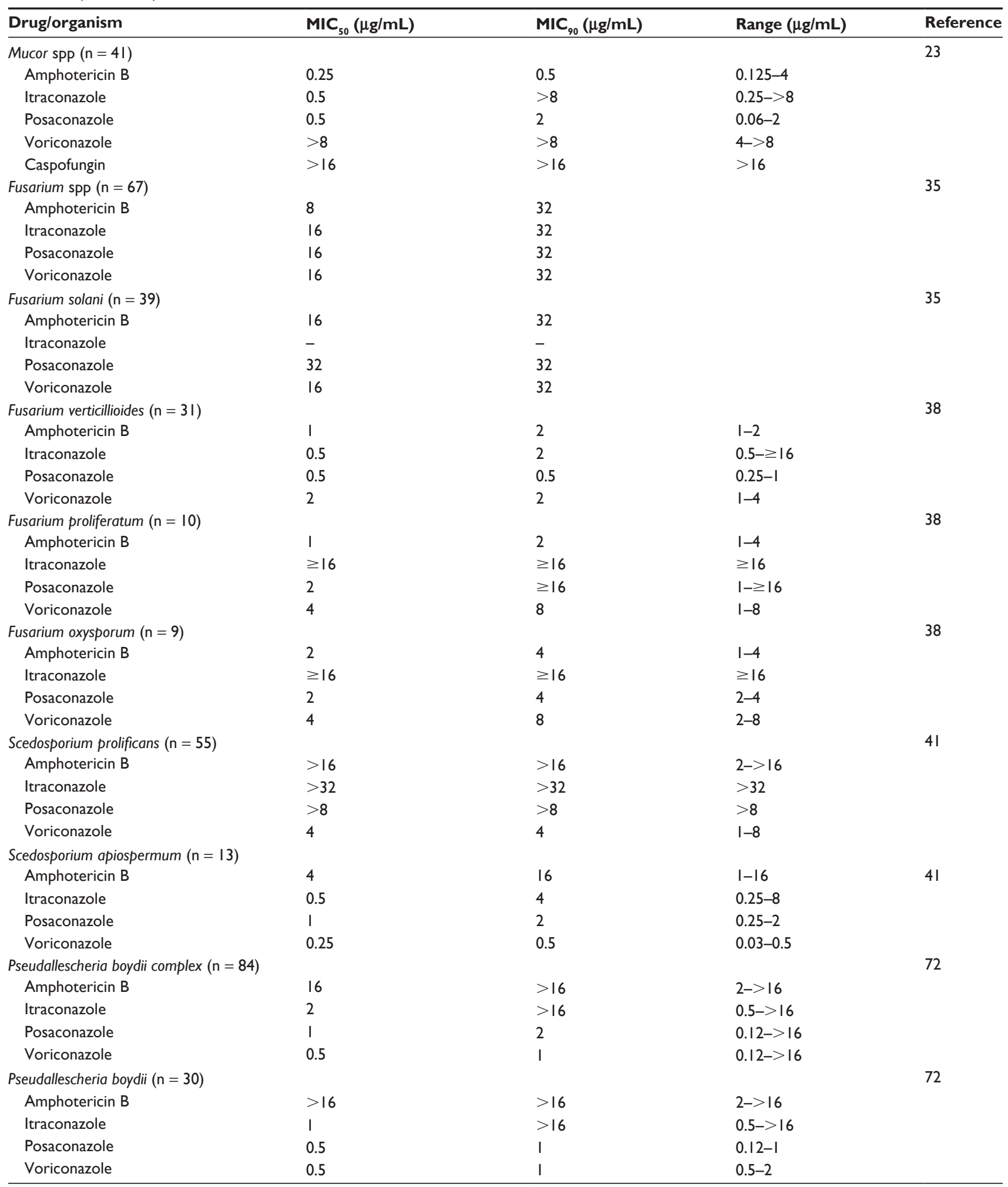

observed. In one collection of 34 itraconazole-resistant A. fumigatus, $74 \%$ were cross-resistant to posaconazole and $65 \%$ were cross-resistant to voriconazole. ${ }^{43}$ Furthermore, it was noted that the position and type of amino acid substitution within the CYP51A protein determined the pattern of azole cross-resistance expressed. For instance, itraconazoleresistant isolates with alterations at codons 98, 138, 431, and 434 exhibited cross-resistance to posaconazole and voriconazole, whereas isolates with substitutions at codons 54 and 216 remained susceptible to voriconazole. ${ }^{43}$ 


\section{Clinical trials \\ Prophylaxis}

The effectiveness of oral posaconazole $200 \mathrm{mg}$ three times daily versus oral fluconazole $400 \mathrm{mg}$ daily or itraconazole $200 \mathrm{mg}$ twice daily was compared as prophylaxis against invasive fungal infections in patients with neutropenia secondary to chemotherapy for acute myelogenous leukemia or myelodysplastic syndrome. ${ }^{44}$ In total, 304 patients were assigned to the posaconazole treatment group, 240 to fluconazole, and 58 to itraconazole. Patients were studied until they fulfilled one of the endpoints, ie, remission from neutropenia, occurrence of invasive fungal infection, or a total of 12 weeks of prophylaxis. Among the patients who were reported to have either a proven or probable invasive fungal infection, seven $(2 \%)$ occurred in the posaconazole group, $25(8 \%)$ occurred in the fluconazole or itraconazole group (95\% confidence interval $[\mathrm{CI}]-9.7,-2.5 ; P<0.001)$. Fewer patients, ie, two (1\%), were also found to experience an invasive aspergillosis infection in the posaconazole group versus $20(7 \%)$ in the fluconazole or itraconazole groups $(95 \% \mathrm{CI}$ $-9.1,-3.1 ; P<0.001)$. The authors also noted a lengthening in survival time among posaconazole-treated subjects $(P=0.04)$. It is important to note that this was not a doubleblinded trial. Although the evaluators were blinded, those making treatment decisions were not and therefore may have been biased. Additionally, the finding that fewer proven or probable Aspergillus infections occurred in the posaconazole group is not surprising because the majority of patients in the comparator group received fluconazole. Unfortunately, not much information was provided regarding those who failed therapy. Although samples were collected for determination of drug levels, these were not correlated with outcome nor was it mentioned if they were used to correct doses for those who may have had subtherapeutic drug levels.

In another study, patients who developed graft-versus-host disease following allogeneic hematopoietic stem cell transplantation were given either posaconazole or fluconazole as prophylaxis against invasive fungal infection ${ }^{45}$ Patients were randomized to receive either posaconazole $200 \mathrm{mg}$ three times daily $(\mathrm{n}=301)$ or fluconazole $400 \mathrm{mg}$ once daily $(\mathrm{n}=299)$ for a fixed 112-day treatment period. At the end of the study period, the authors reported that the incidence of all invasive fungal infections was similar between the groups, ie, posaconazole $5.3 \%$ and fluconazole $9.0 \%(P=0.07)$. However, posaconazole was found to be superior in preventing probable or proven aspergillosis. Only $2.3 \%$ of patients treated with posaconazole were diagnosed with aspergillosis, compared with $7 \%$ of patients in the fluconazole group $(P=0.006)$.
Although overall mortality was similar between the two treatment groups, death secondary to invasive fungal infection was significantly lower among posaconazole-treated subjects ( $1 \%$ versus $4 \%$ in the fluconazole group; $P=0.046$ ). However, it should be noted that criteria for determining cause of death were not provided. Therefore, it is difficult to assess how death secondary to invasive fungal infection was confirmed. This trial was powered under the assumption that 93 patients would experience an invasive fungal infection. In reality, because only 43 cases of invasive fungal infection were noted, only conclusions based on noninferiority can be drawn. Lastly, although the investigators did measure posaconazole plasma concentrations, no correlation was provided between drug levels and efficacy.

\section{Treatment}

The safety and efficacy of posaconazole were analyzed in an open-label trial with patients having fungal infection of the central nervous system that were refractory to or intolerant to standard therapy. ${ }^{46}$ Patients were administered $800 \mathrm{mg}$ daily of posaconazole suspension in divided doses (200 mg four times daily or $400 \mathrm{mg}$ twice daily) for up to one year. Doses were administered with food or a nutritional supplement. Plasma posaconazole concentrations were not measured. A total of 39 patients were included in the final analysis. The most common pathogen isolated was $C$. neoformans $(\mathrm{n}=29)$. Of the 29 patients with cryptococcal disease, 26 had refractory disease that had not responded to a reasonable trial of standard therapy. The remaining 10 patients had infections caused by a variety of fungal pathogens, including Aspergillus spp $(\mathrm{n}=4)$, Pseudallescheria boydii $(\mathrm{n}=2)$, Coccidioides immitis, H. capsulatum, Ramichloridium mackenziei, Apophysomyces elegans plus a Basidiomycetes spp. Fourteen of the 29 patients (48\%) with cryptococcal meningitis were noted to have successful outcomes, comprising four complete responses and 10 partial responses. These rates of response are similar to those noted following salvage therapy with amphotericin B lipid complex and better than those reported with voriconazole. ${ }^{47,48} \mathrm{Of}$ the 15 patients who experienced an unsuccessful outcome, eight were deemed to be treatment failures, six had stable disease, and one was undetermined. It should be noted that the definition for response used in this trial was based solely on resolution of symptoms and radiographic findings, and did not include criteria regarding absence or presence of positive cultures. Among the 10 patients with central nervous system infection due to other fungal species, five responded (two complete and three partial) to posaconazole therapy. Four of 
the patients who did not respond to therapy died within two weeks following posaconazole salvage therapy.

The efficacy of posaconazole salvage therapy in a case series of eight patients with chronic granulomatous disease and invasive mould infections was reported ${ }^{49}$ All patients had received voriconazole prior to enrollment in the study. A causative pathogen was identified in six of the eight subjects. The identified pathogens included Aspergillus spp $(\mathrm{n}=2)$, Phaeoacremonium parasiticum $(\mathrm{n}=2)$, Scedosporium apiospermum $(\mathrm{n}=1)$, and Paecilomyces variotti $(\mathrm{n}=1)$. All patients had infection that involved the lungs. Seven patients received posaconazole $400 \mathrm{mg}$ solution twice daily and one patient received $200 \mathrm{mg}$ three times daily. The mean duration of therapy was 10 months. Monitoring of plasma posaconazole concentrations was not reported. Seven of the eight patients demonstrated a complete response to therapy. One patient with persistent $P$. variotti failed treatment. Long-term therapy with posaconazole was well tolerated, with gastrointestinal symptoms being the most commonly reported adverse event.

A post hoc analysis evaluated the safety and efficacy of posaconazole as salvage therapy for invasive fungal infections in patients following solid organ transplantation. ${ }^{50}$ Investigators evaluated 23 patients who had developed proven or probable invasive fungal infection and were refractory or intolerant to standard antifungal treatments. Patients received posaconazole suspension at a dose of $800 \mathrm{mg}$ daily (200 mg four times daily or $400 \mathrm{mg}$ twice daily) for a mean of 119 days. Complete or partial response to therapy was noted for 13 of 23 (57\%) of patients. Response according to specific pathogen was seven of 12 patients with aspergillosis, two of two with fusariosis, one of one with cryptococcosis, and one of two with zygomycosis. Interestingly, the three patients infected with Candida spp did not respond to posaconazole therapy. One patient was infected with Candida glabrata (posaconazole MIC $=0.125 \mu \mathrm{g} / \mathrm{mL}$ ) and C. krusei (MIC not determined), one with C. glabrata (posaconazole MIC $>8 \mu \mathrm{g} / \mathrm{mL}$ ), and one with Candida parapsilosis (MIC not determined). Plasma posaconazole concentrations were not reported for these three patients. Adverse effects of posaconazole were seen in 12 of the 23 patients, most of which were gastrointestinal events, including mild to moderate nausea and vomiting. Despite only being available as an oral formulation, posaconazole demonstrated good activity as salvage therapy among patients infected with problematic fungal pathogens. However, the lack of response noted with the three Candida spp is concerning, and suggests the possibility of emergence of secondary resistance to posaconazole following exposure to other azoles.
Another post hoc subanalysis was conducted to determine the safety and efficacy of posaconazole in patients with invasive fungal infections and renal impairment. ${ }^{51}$ The analysis included 65 patients from a Phase III trial who had renal impairment, defined as creatinine clearance $<50 \mathrm{~mL} / \mathrm{min}$ or a serum creatinine level $>2 \mathrm{mg} / \mathrm{dL}$, and a control group of 173 patients with acceptable renal function. Patients had either probable or proven refractory invasive fungal infections or were intolerant to standard antifungal therapy. Patients were administered posaconazole suspension $800 \mathrm{mg}$ daily (200 mg four times daily while hospitalized or $400 \mathrm{mg}$ twice daily while outpatients) with food. The most commonly encountered pathogen in both groups was Aspergillus, accounting for $63 \%$ and $38 \%$ of infections in the renally impaired and acceptable renal function groups, respectively. No differences between groups were noted with respect to response (approximately 50\%) or tolerability. Adverse events occurred in $49 \%$ of patients with renal impairment and in $42 \%$ of patients in the control group, with the most common event being nausea. These data suggest that posaconazole is safe and effective in patients with renal impairment. These findings are important owing to concerns about using azoles that contain cyclodextrin in patients with impaired renal function.

Posaconazole has been evaluated in patients with HIV for the treatment of oropharyngeal candidiasis and/or esophageal candidiasis refractory to treatment with either fluconazole or itraconazole. ${ }^{52}$ Patients received posaconazole dosed at either $400 \mathrm{mg}$ twice daily for three days then $400 \mathrm{mg}$ once daily for 25 days or $400 \mathrm{mg}$ twice daily for 28 days. Of the 176 patients in the modified intent-to-treat population, 132 patients (75\%) were considered to have responded clinically to treatment. Mycologic response assessed at week 4 in 126 patients was $36.5 \%$. Rates of clinical response were similar among patients with fluconazole-resistant (73\%) and itraconazoleresistant $(74 \%)$ isolates. The response rates were similar between the two regimens, being $75.3 \%$ for the once-daily regimen and $74.7 \%$ for the twice-daily regimen. However, of the 132 patients who responded initially, a follow-up assessment performed four weeks after treatment completion revealed relapse of infection in 32 of the 40 patients who had taken the once-daily regimen (80\%) and 27 of 40 patients who had taken the twice-daily regimen (68\%). Because it is unlikely that posaconazole will be routinely used in azole-naïve patients with oropharyngeal and/or esophageal candidiasis, the fact that this study enrolled patients with fluconazoleand itraconazole-resistant Candida is significant. Therefore, this study was able to demonstrate that posaconazole may be 
clinically useful against Candida nonresponsive to and/or having reduced susceptibility to fluconazole and itraconazole. Although both posaconazole regimens tested did appear to be efficacious, determination of plasma concentrations and information regarding concurrent food ingestion were not reported. This information would be useful for the determination of an optimal dosing strategy in these indications.

In a head-to-head comparison, patients with HIV and oropharyngeal candidiasis were treated with either posaconazole or fluconazole. ${ }^{53}$ Findings from this study revealed that $200 \mathrm{mg}$ of posaconazole on day 1 followed by $100 \mathrm{mg}$ daily was noninferior to $200 \mathrm{mg}$ of fluconazole on day 1 followed by $100 \mathrm{mg}$ daily. Both medications were administered with food. After 14 days of treatment, clinical success in the modified intent-to-treat group was seen in 155 of $169(91.7 \%)$ patients receiving posaconazole and in 148 of $160(92.5 \%)$ patients receiving fluconazole $(95 \% \mathrm{CI}$ $-6.61 \%, 5.04 \%$ ). Additionally, patients received follow-up on day 42 to determine the rate of relapse. Again, both regimens demonstrated similar rates of clinical relapse, ie, $31.5 \%$ for posaconazole and $38.2 \%$ for fluconazole $(P=0.24)$. However, assessment of mycologic success after 42 days, defined as a yeast culture showing $\leq 20 \mathrm{cfu} / \mathrm{mL}$ of Candida spp, revealed that $40.6 \%$ of patients receiving posaconazole and $26.4 \%$ of patients receiving fluconazole had mycologic success $(P=0.038)$. Although both drugs produce a successful initial outcome, posaconazole was more effective at sustaining a mycologic response after the medication was discontinued. Although this study used clinical and microbiologic endpoints for efficacy evaluation, clinical outcomes may be more relevant from a patient perspective. Because few patients with HIV and candidiasis achieve and maintain fungal eradication, symptom resolution may provide the best marker of success.

The efficacy of posaconazole as salvage therapy has been examined in patients with probable or proven invasive aspergillosis and a hematologic malignancy. ${ }^{54}$ Fifty-three patients were treated with posaconazole $200 \mathrm{mg}$ four times daily while in the hospital and $400 \mathrm{mg}$ twice whilst outpatients. All patients took their doses with either a nutritional supplement or fatty meal. Response rates were compared with contemporary controls treated with either high-dose ( $\geq 7.5 \mathrm{mg} / \mathrm{kg} /$ day) lipid amphotericin $\mathrm{B}(\mathrm{n}=52)$ or caspofungin (70 mg on day 1 followed by $50-100 \mathrm{mg}$ daily) in combination with a high-dose lipid formulation of amphotericin B $(n=38)$. Of the 53 patients treated with posaconazole, $40 \%$ demonstrated a response compared with $8 \%$ of patients treated with amphotericin B and $11 \%$ treated with the combination therapy $(P<0.01)$. Additionally, Aspergillus-related mortality was significantly lower among posaconazole-treated patients at $40 \%$ compared with controls at $65 \%-68 \%(P \leq 0.02)$. According to a multivariate analysis, posaconazole therapy was independently associated with an improved response compared with high-dose lipid amphotericin B (odds ratio [OR] 9.5; 95\% CI, 2.8, 32.5; $P<0.001$ ) and the combination regimen (OR 4.0; 95\% CI, 1.1, 14.5; $P=0.03$ ). Additionally, during 12 weeks of follow-up, posaconazole was associated with an overall higher survival rate compared with the other groups $(P \leq 0.04)$. However, it is important to note that $77.8 \%$ of the patients treated with highdose lipid amphotericin B and the combination of high-dose lipid amphotericin B plus caspofungin had received a regular dose (3-5 mg/kg/day) lipid formulation of amphotericin B as their primary therapy. This caveat is underscored by recent findings that failed to demonstrate an improvement in patient outcomes among those treated for invasive aspergillosis with liposomal amphotericin B at doses of $3 \mathrm{mg} / \mathrm{kg} /$ day and $10 \mathrm{mg} / \mathrm{kg} /$ day. ${ }^{55}$ However, the data do provide evidence that a change in therapy, rather than a dosage increase, should be made if a patient does not respond to primary treatment. Similar findings were noted in an open-label study of patients with invasive aspergillosis refractory to at least seven days of antifungal therapy or intolerant to conventional therapy. ${ }^{56}$ In this trial, outcomes from 107 patients who received posaconazole $800 \mathrm{mg}$ daily (200 $\mathrm{mg}$ four times daily while hospitalized and $400 \mathrm{mg}$ twice daily while outpatients) with food or a nutritional supplement for up to 372 days (median of 56 days) were compared with those in 86 historic controls. Patients were enrolled and received posaconazole if they had a confirmed diagnosis of invasive aspergillosis, and were included in the analysis if they took at least one dose of posaconazole. Control subjects were selected if they had proven or probable invasive aspergillosis and had at least one response assessment during salvage therapy. Control subjects were excluded if they died with 72 hours of initiation of salvage therapy or were receiving mechanical ventilation at baseline. Plasma samples were obtained from patients treated with posaconazole and used for drug concentration determination. Response rates in posaconazole-treated patients were $42 \%$ versus $26 \%$ for control patients $(95 \% \mathrm{CI}$, 1.50, 11.04; $P=0.006)$. Response rates in patients treated with posaconazole who had pulmonary and nonpulmonary aspergillosis were $39 \%$ and $53 \%$, respectively. According to an analysis of plasma concentration versus outcome, it was noted that higher posaconazole concentrations were associated with improved response rates. Patients undergoing 
salvage therapy represent a highly diverse patient population. Although the investigators made good attempts at controlling for population differences, it is important to recognize this variability exists when comparisons are made with historic controls. In this study, one variable that stands out is the fact that $57 \%$ of the controls were treated before 1999 , whereas $81 \%$ of the posaconazole-treated patients were enrolled in 2000-2001. Another limitation of this study is the lack of information regarding baseline severity of illness. Because patients treated with posaconazole had to be treated with an oral formulation, one might argue that clinicians may have been less likely to allow their more severely ill patients to take part in the study.

Posaconazole has also been demonstrated to be efficacious in patients with chronic refractory coccidioidomycosis. ${ }^{57}$ Fifteen patients were identified with coccidioidomycosis who had been treated with a variety of therapies, including amphotericin B. Patients were treated with posaconazole suspension $400 \mathrm{mg}$ twice daily (some patients received $200 \mathrm{mg}$ four times daily while hospitalized) as continuous therapy for 34 to 365 days. Response to therapy was seen in 11 of the 15 participants $(73 \%)$, and four were complete responders. In recipients who responded, an improvement was normally seen between one and six months of treatment. Similar findings were reported in a case series of six patients with refractory coccidioidomycosis. ${ }^{58}$ Patients in this series received posaconazole $800 \mathrm{mg}$ daily $(200 \mathrm{mg}$ four times daily or $400 \mathrm{mg}$ twice daily) in divided doses for 1-2 years. At the end of the study period, five of the six recipients had successful outcomes.

The efficacy of posaconazole was demonstrated for histoplasmosis in a case series of patients who were intolerant or refractory to standard treatment. ${ }^{59}$ Six patients were treated with posaconazole $800 \mathrm{mg}$ /day in divided doses for up to 34 weeks. All recipients had successful clinical outcomes, with improvements seen within the first month of therapy.

The efficacy of posaconazole for the treatment of probable or proven invasive fusariosis was examined in a retrospective analysis of 21 patients who were intolerant or refractory to other therapies. ${ }^{60}$ All patients were treated with posaconazole $800 \mathrm{mg}$ (200 mg four times daily or $400 \mathrm{mg}$ twice daily) administered with food. Ten of the 21 patients $(48 \%)$ had a complete or partial response to therapy. Among patients with leukemia who received posaconazole for more than three days, the response rate was $50 \%$. It should be noted that, unlike several previous studies, subjects in this study were not classified as having a successful outcome if their disease remained stable. Response was higher for patients with leukemia who recovered from myelosuppression compared with those who remained neutropenic (67\% versus $20 \%$ ). Of the six patients with a history of hematopoietic stem cell transplantation, only one patient responded to treatment. Although these results are encouraging, the severity of illness of patients at baseline was not provided. However, it did appear that posaconazole was the least effective among the sickest patients, ie, persistently neutropenic patients with leukemia, and patients (20\%) who underwent hematopoietic stem cell transplantation (17\%). Unfortunately, the infecting Fusarium spp were not reported. This information is vital for extrapolation to a broader population, because several Fusarium spp, such as $F$. solani, exhibit in vitro resistance to posaconazole (Table 1).

Posaconazole has also been examined for the treatment of zygomycosis. ${ }^{61}$ In a retrospective study, 91 patients with proven $(n=22)$ or probable $(n=69)$ zygomycosis who were intolerant or refractory to other antifungals and subsequently treated with posaconazole $800 \mathrm{mg}$ daily (200 mg four times daily or $400 \mathrm{mg}$ twice daily) were evaluated. All posaconazole doses were administered with food or a nutritional supplement. After 12 weeks of treatment, $60 \%$ of patients had a complete or partial response and $21 \%$ had stable disease. It was noted that success rates were similar regardless of predisposing conditions or sites of infection. Owing to the relatively small number of Zygomycetes species, determination of statistical differences in outcome with respect to infecting species was not feasible. However, observed rates of success did vary from $28.6 \%$ with Rhizomucor $\operatorname{spp}(\mathrm{n}=7)$ to $100 \%$ with Absidia $\operatorname{spp}(\mathrm{n}=2)$. For the two species having the largest number of isolates, the response rates were $52 \%$ for patients infected with Rhizopus spp $(\mathrm{n}=25)$ and $76.5 \%$ with Mucor spp $(\mathrm{n}=17)$. Although 64 of the 91 patients in this series underwent surgical debridement, success rates were similar for patients who did (61\%) and did not (62\%) undergo this procedure. A major limitation of this study was the fact that clinicians from many diverse centers were asked to complete questionnaires about their patients subsequent to treatment. Therefore, differences in institutional practices and recall bias limit the strength of the data. Despite these limitations, the data do provide a glimpse into the use of posaconazole for Zygomycoses.

\section{Adverse events and tolerability}

The most common adverse events for posaconazole, as listed in the package insert, are increased hepatic enzymes, hepatocellular damage, bilirubinemia, nausea, and vomiting. ${ }^{7}$ A summary of the adverse events noted with posaconazole, 
fluconazole, and itraconazole are presented in Table 2. Some patients in the clinical trials received posaconazole up to $1600 \mathrm{mg} /$ day. $^{7}$ No difference was seen in adverse events between patients receiving the high dosages and those receiving lower dosages. In addition, there is one reported accidental overdose in a patient who consumed $1200 \mathrm{mg}$ twice daily for three days, with no adverse events seen.

The long-term safety of posaconazole was examined via comparison of 109 patients who received posaconazole for six months or longer and 319 patients receiving posaconazole for less than six months. ${ }^{62}$ Among patients receiving posaconazole for six months or more, slightly more anorexia, increased serum glutamic pyruvic transaminase levels, headaches, and menstrual disorders were observed. However, the authors stated that they could not find any trend in these events that suggested an increased risk of adverse effects with longer treatment. They also noted that no trends of adverse effects on laboratory values or increased risk of cardiac events were seen with longer exposure to the medication.

\section{Drug interactions}

Posaconazole is metabolized by uridine diphosphate glucuronidation and is a substrate for p-glycoprotein efflux. Therefore, inducers and inhibitors of these paths, such as efavirenz, may affect the plasma concentrations of posaconazole. ${ }^{7}$ Some medications that may decrease the bioavailability of posaconazole because of their effect on gastric $\mathrm{pH}$ or motility include cimetidine, esomeprazole, and metoclopramide. ${ }^{10}$ Posaconazole is an inhibitor of CYP3A4 and may increase levels of medications metabolized through this pathway. As a result, medications such as midazolam, ritonavir, and atazanavir, and the calcineurin inhibitors, cyclosporine and tacrolimus, require frequent monitoring when coadministered with posaconazole. ${ }^{7,50,51}$ For the same reason, the coadministration of posaconazole and sirolimus is contraindicated. When administered concurrently, a significant interaction is noted between posaconazole and rifabutin. ${ }^{63}$ This interaction results in a $43 \%(P=0.005)$ decrease in peak plasma concentration $\left(\mathrm{C}_{\max }\right)$ and a $49 \%(P=0.008)$ decrease in the

Table 2 Adverse events of posaconazole compared with fluconazole/itraconazole ${ }^{7}$

\begin{tabular}{lll}
\hline & Posaconazole & $\begin{array}{l}\text { Fluconazolel } \\
\text { itraconazole }\end{array}$ \\
\hline Overall adverse events & $34 \%$ & $34 \%$ \\
Nausea & $7 \%$ & $8 \%$ \\
Vomiting & $5 \%$ & $7 \%$ \\
Bilirubinemia & $2 \%$ & $3 \%$ \\
Increased hepatic enzymes & $2 \%$ & $1 \%$ \\
\hline
\end{tabular}

AUC of posaconazole. Coadministration also produced an increase of $31 \%(P=0.016)$ in $\mathrm{C}_{\max }$ and a $72 \%(P<0.001)$ increase in AUC of rifabutin, probably due to inhibition of CYP3A4. Therefore, the concomitant use of rifabutin and posaconazole should generally be avoided, owing to the risk of breakthrough fungal infections secondary to reduced posaconazole exposure and the increased risk for adverse effects from rifabutin, such as uveitis and leukopenia. Posaconazole may also increase concentrations of vinca alkaloids, digoxin, HMG-CoA reductase inhibitors metabolized by CYP3A4, and calcium channel blockers metabolized by CYP3A4. ${ }^{7}$

Coadministration of posaconazole and phenytoin resulted in a $44 \%(P=0.012)$ decrease in $\mathrm{C}_{\max }$ and a $52 \%(P=0.007)$ decrease in the AUC of posaconazole. ${ }^{64}$ Although phenytoin levels were not significantly elevated, there was inconsistency between patients, and coadministration could affect phenytoin levels. Therefore, phenytoin levels should be monitored while the drugs are being concurrently administered. The mechanism for this interaction may be due to the induction of uridine diphosphate glucuronosyltransferase activity by phenytoin. Because coadministration can decrease posaconazole levels, the concomitant use of phenytoin and posaconazole should be avoided unless the benefit outweighs the risk.

A review of drug-drug interactions with systemic triazole antifungals describes medications that are contraindicated for use with posaconazole. ${ }^{65}$ Astemizole, halofantrine, bepridil, sertindole, cisapride, quinidine, pimozide, and terfenadine are contraindicated due to a potential for QT interval prolongation and risk of torsades de pointes. Ergot alkaloids are contraindicated for use with posaconazole because the latter may increase the patient's exposure to the ergot alkaloid, causing ergotism. ${ }^{7}$

\section{Therapeutic drug monitoring}

Owing to the high inter- and intrapatient variability associated with plasma posaconazole concentrations, some clinicians have advocated the use of therapeutic drug monitoring to ensure that adequate drug levels are achieved. Although several authors have documented variability in plasma posaconazole concentrations, few data have been published that specifically correlate drug levels with clinical efficacy. ${ }^{66}$ One retrospective study evaluated the clinical efficacy of posaconazole among 54 patients who had plasma concentrations determined during therapy. ${ }^{67}$ These authors defined a low plasma concentration of posaconazole as being $<500 \mathrm{ng} / \mathrm{mL}$. Accordingly, it was reported that $44 \%$ of patients receiving a prophylactic regimen of $200 \mathrm{mg}$ three times daily and $22 \%$ of patients administered a curative regimen of $400 \mathrm{mg}$ twice 
daily experienced low posaconazole plasma concentrations. Among the 36 patients who received posaconazole prophylaxis, only two developed a possible invasive fungal infection. Both of these patients were noted to have low plasma posaconazole concentrations. Of the 18 patients treated curatively with posaconazole, two patients with low plasma posaconazole concentrations had a complete response, one died from an unrelated cause, and one exhibited stable disease. In a prospective trial examining the efficacy of salvage therapy with posaconazole for the treatment of invasive aspergillosis, plasma concentrations of posaconazole were assessed and related to outcome. ${ }^{56}$ In this study, it was observed that patients in the highest concentration quartile, with a mean plasma concentration of $1250 \mathrm{ng} / \mathrm{mL}$, exhibited the best response rate at $75 \%$. Conversely, those in the lowest concentration quartile, with a mean plasma concentration $134 \mathrm{ng} / \mathrm{mL}$, exhibited the lowest response rate at $24 \%$. Because there was considerable variability with respect to interpatient plasma posaconazole concentrations, the authors were not able to recommend a definitive target concentration. Rather, the suggestion was made that, whenever possible, efforts should be made to optimize posaconazole absorption (ie, take dose with food or a nutritional supplement).

Acknowledging the tremendous variability associated with the bioavailability of posaconazole and the potential for poor outcomes secondary to suboptimal exposure, it may be recommended that plasma posaconazole concentrations be evaluated to ensure that adequate absorption occurs. Currently, it is recommended that plasma posaconazole concentrations $>700 \mathrm{ng} / \mathrm{mL}$ be targeted. ${ }^{68,69}$ Additional studies are needed to determine if this is the optimal target concentration for efficacy.

\section{Patient-focused perspectives}

To determine the cost-effectiveness of posaconazole versus other azoles for the prevention of invasive fungal infections, an analysis was conducted in high-risk neutropenic patients with acute myeloid leukemia and myelodysplastic syndrome. ${ }^{70}$ The total cost for posaconazole treatment and prophylaxis was less than the costs associated with fluconazole and itraconazole. With respect to quality of life, prophylaxis with posaconazole resulted in a gain of 0.08 quality-adjusted life years in comparison with prophylaxis using other azoles. Another study has also examined the costeffectiveness of posaconazole prophylaxis against invasive fungal infection..$^{71}$ According to this report, treatment with posaconazole resulted in fewer invasive fungal infections per patient compared with fluconazole or itraconazole therapy
(0.05 versus 0.11$)$. Based on their model, they determined that posaconazole is very likely to be cost-effective compared with fluconazole or itraconazole in preventing invasive fungal infections in neutropenic patients. Using an economic model, they also found that use of posaconazole provides an additional 0.08 undiscounted life-years per patient over fluconazole or itraconazole. The authors also noted that, even though the cost of prophylaxis was higher in the posaconazole group, costs associated with treating invasive fungal infections were lower. The authors estimated that posaconazole prophylaxis resulted in a savings of approximately $\$ 600$ per patient in discounted medical costs.

\section{Conclusion}

Posaconazole is a broad-spectrum azole antifungal that has demonstrated clinical efficacy against a variety of difficult-to-treat fungal infections. The activity of posaconazole against various moulds is particularly exciting. However, saturable absorption and lack of an intravenous formulation may limit the utility of posaconazole in some patient populations, especially those who are severely ill. Furthermore, clinicians will need to be vigilant for breakthrough infections, which may be caused by problematic pathogens resistant to or outside the spectrum of activity of posaconazole.

\section{Disclosure}

The authors report no conflicts of interest in this work.

\section{References}

1. Maertens JA. History of the development of azole derivatives. Clin Microbiol Infect. 2004;10 Suppl 1:1-10.

2. Warnock DW. Trends in the epidemiology of invasive fungal infections. Nippon Ishinkin Gakkai Zasshi. 2007;48(1):1-12.

3. Mishra NN, Prasad T, Sharma N, et al. Pathogenicity and drug resistance in Candida albicans and other yeast species. A review. Acta Microbiol Immunol Hung. 2007;54(3):201-235.

4. Cornely OA. Aspergillus to Zygomycetes: Causes, risk factors, prevention, and treatment of invasive fungal infections. Infection. 2008; 36(4):296-313.

5. Girmenia C. New generation azole antifungals in clinical investigation. Expert Opin Investig Drugs. 2009;18(9):1279-1295.

6. Snelders E, Huis In 't Veld RA, Rijs AJ, Kema GH, Melchers WJ, Verweij PE. Possible environmental origin of resistance of Aspergillus fumigatus to medical triazoles. Appl Environ Microbiol. 2009; 75(12):4053-4057.

7. Posaconazole [package insert]. Kenilworth NJ: Schering-Plough; 2008.

8. Hof H. A new, broad-spectrum azole antifungal: Posaconazole mechanisms of action and resistance, spectrum of activity. Mycoses. 2006;49 Suppl 1:2-6.

9. Perea S, Lopez-Ribot JL, Kirkpatrick WR, et al. Prevalence of molecular mechanisms of resistance to azole antifungal agents in Candida albicans strains displaying high-level fluconazole resistance isolated from human immunodeficiency virus-infected patients. Antimicrob Agents Chemother. 2001;45(10):2676-2684. 
10. Pfaller MA, Messer SA, Hollis RJ, Jones RN, Diekema DJ. In vitro activities of ravuconazole and voriconazole compared with those of four approved systemic antifungal agents against 6,970 clinical isolates of Candida spp. Antimicrob Agents Chemother. 2002;46(6):1723-1727.

11. Courtney R, Wexler D, Radwanski E, Lim J, Laughlin M. Effect of food on the relative bioavailability of two oral formulations of posaconazole in healthy adults. Br J Clin Pharmacol. 2004;57(2):218-222.

12. Sansone-Parsons A, Krishna G, Simon J, et al. Effects of age, gender, and race/ethnicity on the pharmacokinetics of posaconazole in healthy volunteers. Antimicrob Agents Chemother. 2007;51(2):495-502.

13. Krishna G, Moton A, Ma L, Medlock MM, McLeod J. Pharmacokinetics and absorption of posaconazole oral suspension under various gastric conditions in healthy volunteers. Antimicrob Agents Chemother. 2009; 53(3):958-966.

14. Kohl V, Muller C, Cornely OA, et al. Factors influencing pharmacokinetics of prophylactic posaconazole in patients undergoing allogeneic stem cell transplantation. Antimicrob Agents Chemother. 2010; 54(1):207-212.

15. Gubbins PO, Krishna G, Sansone-Parsons A, et al. Pharmacokinetics and safety of oral posaconazole in neutropenic stem cell transplant recipients. Antimicrob Agents Chemother. 2006;50(6):1993-1999.

16. Ullmann AJ, Cornely OA, Burchardt A, et al. Pharmacokinetics, safety, and efficacy of posaconazole in patients with persistent febrile neutropenia or refractory invasive fungal infection. Antimicrob Agents Chemother. 2006;50(2):658-666.

17. Courtney R, Pai S, Laughlin M, Lim J, Batra V. Pharmacokinetics, safety, and tolerability of oral posaconazole administered in single and multiple doses in healthy adults. Antimicrob Agents Chemother. 2003;47(9):2788-2795.

18. Conte JE Jr, Golden JA, Krishna G, McIver M, Little E, Zurlinden E. Intrapulmonary pharmacokinetics and pharmacodynamics of posaconazole at steady state in healthy subjects. Antimicrob Agents Chemother. 2009;53(2):703-707.

19. Conte JE Jr, DeVoe C, Little E, Golden JA. Steady-state intrapulmonary pharmacokinetics and pharmacodynamics of posaconazole in lung transplant recipients. Antimicrob Agents Chemother. 2010; 54(9):3609-3613.

20. Krieter P, Flannery B, Musick T, Gohdes M, Martinho M, Courtney R. Disposition of posaconazole following single-dose oral administration in healthy subjects. Antimicrob Agents Chemother. 2004; 48(9):3543-3551.

21. Courtney R, Sansone A, Smith W, et al. Posaconazole pharmacokinetics, safety, and tolerability in subjects with varying degrees of chronic renal disease. J Clin Pharmacol. 2005;45(2):185-192.

22. Moton A, Krishna G, Ma L, et al. Pharmacokinetics of a single dose of the antifungal posaconazole as oral suspension in subjects with hepatic impairment. Curr Med Res Opin. 2010;26(1):1-7.

23. Almyroudis NG, Sutton DA, Fothergill AW, Rinaldi MG, Kusne S. In vitro susceptibilities of 217 clinical isolates of zygomycetes to conventional and new antifungal agents. Antimicrob Agents Chemother. 2007;51(7):2587-2590.

24. Cuenca-Estrella M, Gomez-Lopez A, Mellado E, Buitrago MJ, Monzon A, Rodriguez-Tudela JL. Head-to-head comparison of the activities of currently available antifungal agents against 3,378 Spanish clinical isolates of yeasts and filamentous fungi. Antimicrob Agents Chemother. 2006;50(3):917-921.

25. Dannaoui E, Meletiadis J, Mouton JW, Meis JF, Verweij PE. In vitro susceptibilities of zygomycetes to conventional and new antifungals. J Antimicrob Chemother. 2003;51(1):45-52.

26. Diekema DJ, Messer SA, Hollis RJ, Jones RN, Pfaller MA. Activities of caspofungin, itraconazole, posaconazole, ravuconazole, voriconazole, and amphotericin B against 448 recent clinical isolates of filamentous fungi. J Clin Microbiol. 2003;41(8):3623-3626.

27. Espinel-Ingroff A. Comparison of in vitro activities of the new triazole SCH56592 and the echinocandins MK-0991 (L-743, 872) and LY303366 against opportunistic filamentous and dimorphic fungi and yeasts. J Clin Microbiol. 1998;36(10):2950-2956.
28. Lortholary O, Dannaoui E, Raoux D, et al. In vitro susceptibility to posaconazole of 1,903 yeast isolates recovered in France from 2003 to 2006 and tested by the method of the European committee on antimicrobial susceptibility testing. Antimicrob Agents Chemother. 2007; 51(9):3378-3380.

29. Manavathu EK, Cutright JL, Loebenberg D, Chandrasekar PH. A comparative study of the in vitro susceptibilities of clinical and laboratory-selected resistant isolates of Aspergillus spp. to amphotericin B, itraconazole, voriconazole and posaconazole (SCH 56592). JAntimicrob Chemother. 2000;46(2):229-234.

30. Ostrosky-Zeichner L, Rex JH, Pappas PG, et al. Antifungal susceptibility survey of 2,000 bloodstream Candida isolates in the United States. Antimicrob Agents Chemother. 2003;47(10):3149-3154.

31. Pfaller MA, Diekema DJ. Rare and emerging opportunistic fungal pathogens: Concern for resistance beyond Candida albicans and Aspergillus fumigatus. J Clin Microbiol. 2004;42(10):4419-4431.

32. Pfaller MA, Messer SA, Boyken L, et al. In vitro activities of voriconazole, posaconazole, and fluconazole against 4,169 clinical isolates of Candida spp. and Cryptococcus neoformans collected during 2001 and 2002 in the ARTEMIS global antifungal surveillance program. Diagn Microbiol Infect Dis. 2004;48(3):201-205.

33. Pfaller MA, Messer SA, Hollis RJ, Jones RN. In vitro activities of posaconazole (Sch 56592) compared with those of itraconazole and fluconazole against 3,685 clinical isolates of Candida spp. and Cryptococcus neoformans. Antimicrob Agents Chemother. 2001;45(10): 2862-2864.

34. Pfaller MA, Messer SA, Hollis RJ, Jones RN. Antifungal activities of posaconazole, ravuconazole, and voriconazole compared to those of itraconazole and amphotericin B against 239 clinical isolates of Aspergillus spp. and other filamentous fungi: Report from SENTRY Antimicrobial Surveillance Program, 2000. Antimicrob Agents Chemother. 2002;46(4):1032-1037.

35. Sabatelli F, Patel R, Mann PA, et al. In vitro activities of posaconazole, fluconazole, itraconazole, voriconazole, and amphotericin B against a large collection of clinically important molds and yeasts. Antimicrob Agents Chemother. 2006;50(6):2009-2015.

36. Sun QN, Fothergill AW, McCarthy DI, Rinaldi MG, Graybill JR. In vitro activities of posaconazole, itraconazole, voriconazole, amphotericin $\mathrm{B}$, and fluconazole against 37 clinical isolates of zygomycetes. Antimicrob Agents Chemother. 2002;46(5):1581-1582.

37. Tan AL, Chan KS. In vitro activities of antifungal drugs against yeasts isolated from blood cultures and moulds isolated from various clinically significant sites in Singapore. Ann Acad Med Singapore. 2008; 37(10):841-846.

38. Tortorano AM, Prigitano A, Dho G, et al. Species distribution and in vitro antifungal susceptibility patterns of 75 clinical isolates of Fusarium spp. from northern Italy. Antimicrob Agents Chemother. 2008;52(7):2683-2685.

39. Pfaller MA, Diekema DJ, Gibbs DL, et al. Results from the ARTEMIS DISK Global Antifungal Surveillance study, 1997 to 2005: An 8.5-year analysis of susceptibilities of Candida species and other yeast species to fluconazole and voriconazole determined by CLSI standardized disk diffusion testing. J Clin Microbiol. 2007;45(6): 1735-1745.

40. Pfaller MA, Messer SA, Boyken L, et al. In vitro survey of triazole cross-resistance among more than 700 clinical isolates of Aspergillus species. J Clin Microbiol. 2008;46(8):2568-2572.

41. Meletiadis J, Meis JF, Mouton JW, Rodriquez-Tudela JL, Donnelly JP, Verweij PE. In vitro activities of new and conventional antifungal agents against clinical Scedosporium isolates. Antimicrob Agents Chemother. 2002;46(1):62-68.

42. Arendrup MC, Mavridou E, Mortensen KL, et al. Development of azole resistance in Aspergillus fumigatus during azole therapy associated with change in virulence. PLoS One. 2010;5(4):e10080.

43. Howard SJ, Cerar D, Anderson MJ, et al. Frequency and evolution of azole resistance in Aspergillus fumigatus associated with treatment failure. Emerg Infect Dis. 2009;15(7):1068-1076. 
44. Cornely OA, Maertens J, Winston DJ, et al. Posaconazole vs fluconazole or itraconazole prophylaxis in patients with neutropenia. $N$ Engl J Med. 2007:356(4):348-359.

45. Ullmann AJ, Lipton JH, Vesole DH, et al. Posaconazole or fluconazole for prophylaxis in severe graft-versus-host disease. $N \mathrm{Engl} \mathrm{J} \mathrm{Med.}$ 2007;356(4):335-347.

46. Pitisuttithum P, Negroni R, Graybill JR, et al. Activity of posaconazole in the treatment of central nervous system fungal infections. $J$ Antimicrob Chemother. 2005;56(4):745-755.

47. Walsh TJ, Hiemenz JW, Seibel NL, et al. Amphotericin B lipid complex for invasive fungal infections: Analysis of safety and efficacy in 556 cases. Clin Infect Dis. 1998;26(6):1383-1396.

48. Perfect JR, Marr KA, Walsh TJ, et al. Voriconazole treatment for lesscommon, emerging, or refractory fungal infections. Clin Infect Dis. 2003;36(9):1122-1131.

49. Segal BH, Barnhart LA, Anderson VL, Walsh TJ, Malech HL, Holland SM. Posaconazole as salvage therapy in patients with chronic granulomatous disease and invasive filamentous fungal infection. Clin Infect Dis. 2005;40(11):1684-1688.

50. Alexander BD, Perfect JR, Daly JS, et al. Posaconazole as salvage therapy in patients with invasive fungal infections after solid organ transplant. Transplantation. 2008;86(6):791-796.

51. Hachem RY, Langston AA, Graybill JR, et al. Posaconazole as salvage treatment of invasive fungal infections in patients with underlying renal impairment. J Antimicrob Chemother. 2008;62(6):1386-1391.

52. Skiest DJ, Vazquez JA, Anstead GM, et al. Posaconazole for the treatment of azole-refractory oropharyngeal and esophageal candidiasis in subjects with HIV infection. Clin Infect Dis. 2007;44(4):607-614.

53. Vazquez JA, Skiest DJ, Nieto L, et al. A multicenter randomized trial evaluating posaconazole versus fluconazole for the treatment of oropharyngeal candidiasis in subjects with HIV/AIDS. Clin Infect Dis. 2006;42(8):1179-1186.

54. Raad, II, Hanna HA, Boktour M, et al. Novel antifungal agents as salvage therapy for invasive aspergillosis in patients with hematologic malignancies: Posaconazole compared with high-dose lipid formulations of amphotericin B alone or in combination with caspofungin. Leukemia. 2008;22(3):496-503

55. Cornely OA, Maertens J, Bresnik M, et al. Liposomal amphotericin $\mathrm{B}$ as initial therapy for invasive mold infection: A randomized trial comparing a high-loading dose regimen with standard dosing (AmBiLoad trial). Clin Infect Dis. 2007;44(10):1289-1297.

56. Walsh TJ, Raad I, Patterson TF, et al. Treatment of invasive aspergillosis with posaconazole in patients who are refractory to or intolerant of conventional therapy: An externally controlled trial. Clin Infect Dis. 2007;44(1):2-12.

57. Stevens DA, Rendon A, Gaona-Flores V, et al. Posaconazole therapy for chronic refractory coccidioidomycosis. Chest. 2007;132(3):952-958.

58. Anstead GM, Corcoran G, Lewis J, Berg D, Graybill JR. Refractory coccidioidomycosis treated with posaconazole. Clin Infect Dis. 2005; 40(12):1770-1776.
59. Restrepo A, Tobon A, Clark B, et al. Salvage treatment of histoplasmosis with posaconazole. J Infect. 2007;54(4):319-327.

60. Raad, II, Hachem RY, Herbrecht R, et al. Posaconazole as salvage treatment for invasive fusariosis in patients with underlying hematologic malignancy and other conditions. Clin Infect Dis. 2006;42(10): 1398-1403.

61. van Burik JA, Hare RS, Solomon HF, Corrado ML, Kontoyiannis DP. Posaconazole is effective as salvage therapy in zygomycosis: A retrospective summary of 91 cases. Clin Infect Dis. 2006;42(7): e61-e65.

62. Raad, II, Graybill JR, Bustamante AB, et al. Safety of long-term oral posaconazole use in the treatment of refractory invasive fungal infections. Clin Infect Dis. 2006;42(12):1726-1734.

63. Krishna G, Parsons A, Kantesaria B, Mant T. Evaluation of the pharmacokinetics of posaconazole and rifabutin following coadministration to healthy men. Curr Med Res Opin. 2007;23(3): 545-552.

64. Krishna G, Sansone-Parsons A, Kantesaria B. Drug interaction assessment following concomitant administration of posaconazole and phenytoin in healthy men. Curr Med Res Opin. 2007;23(6):1415-1422.

65. Nivoix Y, Leveque D, Herbrecht R, Koffel JC, Beretz L, Ubeaud-Sequier G. The enzymatic basis of drug-drug interactions with systemic triazole antifungals. Clin Pharmacokinet. 2008;47(12): 779-792.

66. Thompson GR 3rd, Rinaldi MG, Pennick G, Dorsey SA, Patterson TF, Lewis JS 2nd. Posaconazole therapeutic drug monitoring: A reference laboratory experience. Antimicrob Agents Chemother. 2009;53(5): 2223-2224.

67. Lebeaux D, Lanternier F, Elie C, et al. Therapeutic drug monitoring of posaconazole: A monocentric study with 54 adults. Antimicrob Agents Chemother. 2009;53(12):5224-5229.

68. Jang SH, Colangelo PM, Gobburu JV. Exposure-response of posaconazole used for prophylaxis against invasive fungal infections: Evaluating the need to adjust doses based on drug concentrations in plasma. Clin Pharmacol Ther. 2010;88(1):115-119.

69. Institute SPR. Posaconazole FDA briefing document. 2005 Available from: http://www.accessdata.fda.gov/drugsatfda_docs/ nda/2006/022003s000_Noxafil_MedR.pdf. Accessed 2010 Oct 9.

70. Stam WB, O'Sullivan AK, Rijnders B, et al. Economic evaluation of posaconazole vs standard azole prophylaxis in high risk neutropenic patients in the Netherlands. Eur J Haematol. 2008;81(6):467-474.

71. O'Sullivan AK, Pandya A, Papadopoulos G, et al. Cost-effectiveness of posaconazole versus fluconazole or itraconazole in the prevention of invasive fungal infections among neutropenic patients in the United States. Value Health. 2009 Jun 9. [Epub ahead of print].

72. Gilgado F, Serena C, Cano J, Gene J, Guarro J. Antifungal susceptibilities of the species of the Pseudallescheria boydii complex. Antimicrob Agents Chemother. 2006;50(12):4211-4213.
Drug Design, Development and Therapy

\section{Publish your work in this journal}

Drug Design, Development and Therapy is an international, peerreviewed open-access journal that spans the spectrum of drug design and development through to clinical applications. Clinical outcomes, patient safety, and programs for the development and effective, safe, and sustained use of medicines are a feature of the journal, which has

\section{Dovepress}

also been accepted for indexing on PubMed Central. The manuscript management system is completely online and includes a very quick and fair peer-review system, which is all easy to use. Visit http:// www.dovepress.com/testimonials.php to read real quotes from published authors. 